\title{
Adrenal function and high dose inhaled corticosteroids for asthma
}

Children's Respiratory Unit, Division of Paediatrics, United Medical and Dental Schools of Guy's and St Thomas' Hospitals, University of London, London

P K Yiallouros

A D Milner

Department of Chemical Pathology, University College

London Hospitals,

London

E Conway

J W Honour

Correspondence to: Professor AD Milner, Department of Paediatrics, St Thomas' Hospital, Lambeth Palace Road, London SE1 7EH.

Accepted 31 January 1997

Panayiotis K Yiallouros, Anthony D Milner, Elvira Conway, John W Honour

\begin{abstract}
Objective-To investigate effects on adrenal function of fluticasone, a recently released inhaled steroid preparation with lower systemic bioavailability than beclomethasone dipropionate.

Methods-34 children on high doses (400$909 \mu \mathrm{g} / \mathrm{m}^{2} / \mathrm{d}$ ) of inhaled beclomethasone dipropionate or budesonide were recruited into a double blind, crossover study investigating the effects on adrenal function of beclomethasone and fluticasone propionate, given using a standard spacer (Volumatic). The 24 hour excretion rates of total cortisol and cortisol metabolites were determined at baseline (after a two week run in), after six weeks treatment with an equal dose of beclomethasone, and after six weeks of treatment with half the dose of fluticasone, both given through a spacer device.
\end{abstract}

Results-The comparison of effects between fluticasone and beclomethasone during treatment periods, although favouring fluticasone in all measured variables, reached significance only after correction for urinary creatinine excretion (tetrahydrocortisol and 5 $\alpha$-tetrahydrocortisol geometric means: $424 v 341$ $\left.\mu \mathrm{g} / \mathrm{m}^{2} / \mathrm{d}\right)$. The baseline data showed adrenal suppression in the children taking beclomethasone (total cortisol geometric means: $975 v 1542 \mu \mathrm{g} / \mathrm{d}$ ) and a dose related suppression in the children taking budesonide. Suppressed adrenal function in the children who were taking beclomethasone at baseline subsequently improved with fluticasone and beclomethasone during treatment periods.

Conclusions-Fluticasone is less likely to suppress adrenal function than beclomethasone at therapeutically equivalent doses. The baseline data also support the claim that spacer devices should be used for the administration of high doses of inhaled topical steroids.

(Arch Dis Child 1997;76:405-410)

Keywords: inhaled corticosteroids; adrenal function; spacer devices

The increasing use of inhaled corticosteroids for the treatment of chronic asthma has renewed interest in their safety, and numerous studies have been done to investigate their effects on the hypothalamic-pituitary-adrenal axis, bone metabolism, and growth over the last few years. ${ }^{12}$ Most studies of the effects on the hypothalamic-pituitary-adrenal axis have measured early morning plasma cortisol levels, a rather insensitive measure of adrenal function, and gave reassuring results. ${ }^{3-5}$ However, adrenocortical output has a circadian rhythm, so that a more appropriate way of assessing function is to measure cortisol excretion for an extended period. At least two studies in children have assessed the integrated concentration of plasma cortisol over 24 and six hours and found that doses of both beclomethasone diproprionate and budesonide as low as 400 $\mu \mathrm{g} / \mathrm{d}$ can induce significant reduction in spontaneous diurnal cortisol secretion. ${ }^{6-8} \mathrm{Al}-$ though reliable, this technique is invasive. As a result many investigators have chosen to obtain an index of the total diurnal production of cortisol metabolites by measuring the free cortisol in 24 hour urine collections. ${ }^{9-11}$ However, the analysis of all cortisol metabolites in a 24 hour urine collection gives a more reliable index of daily hormonal production. ${ }^{12}$ Two previous studies have used gas chromatography to measure all or most of the cortisol metabolites excreted in urine and found a dose related suppression of the basal adrenal function in children taking inhaled beclomethasone. ${ }^{13}{ }^{14}$ The adrenal suppression was evident in approximately $50 \%$ of the children who were taking $400 \mu \mathrm{g} / \mathrm{m}^{2} / \mathrm{d}$ or more of inhaled beclomethasone diproprionate. ${ }^{14}$

Systemic effects of inhaled corticosteroids are due to absorption within the lung and in the gastrointestinal tract. As up to $90 \%$ of the dose is swallowed, ${ }^{15}$ it is possible to reduce the risk of potential side effects by selecting an inhaled corticosteroid with limited gastrointestinal absorption. The use of a spacer device is also claimed to be helpful as the ratio between the amount of drug deposited in the mouth and upper airway and the dose entering the lung is then much lower. ${ }^{16}{ }^{17}$

Fluticasone propionate is a new topical inhaled corticosteroid which has been shown to be twice as potent as beclomethasone..$^{51819}$ Fluticasone has also been shown to have very limited oral bioavailability and extensive first pass hepatic metabolism. ${ }^{20}{ }^{21}$ This raises the possibility that it may have a lesser systemic effect than the other inhaled topical corticosteroids on the market for the same therapeutic effect.

This study was therefore designed to compare the adrenal effects of therapeutically 
equivalent doses of beclomethasone and fluticasone. In addition we wished to assess the effects of each of these treatments on twice daily peak expiratory flow rates (PEF), asthma symptom scores, $\beta_{2}$ agonist rescue medication usage, and clinic lung function measurements.

\section{Methods}

PATIENTS

Thirty four children ( 23 boys and 11 girls) with a clinical history of severe, albeit stable, chronic asthma took part in this study. The patients were recruited from the children's outpatients clinics at St Thomas' and Guy's Hospitals in London and were taking either budesonide (subgroup A: 19 patients) or inhaled beclomethasone (subgroup B: 15 patients) through conventional, that is, direct inhalation, devices for at least three months before their entry to the study. The patients in group A (median age 7.3 years, range: 5 to 12.4 years) were on a median dose of budesonide of $519 \mu \mathrm{g} / \mathrm{m}^{2} / \mathrm{d}$ (range: 412 to $909 \mu \mathrm{g} / \mathrm{m}^{2} / \mathrm{d}$ ). The patients in group B (median age 8.8 years, range: 6 to 13.1 years) were on a median dose of beclomethasone of $588 \mu \mathrm{g} / \mathrm{m}^{2} / \mathrm{d}$ (range: 400 to $869 \mu \mathrm{g} / \mathrm{m}^{2} /$ d). None of the patients had received treatment with oral corticosteroids for longer than 10 consecutive days, or 20 days or more in total, during the previous year, and none had received any oral corticosteroid treatment during the previous three months. Also, none of the patients had used topical corticosteroids for skin disorders during the previous three months. All patients were continent and were able, with parental help, to use the metered dose inhaler correctly, fill in diary cards, and record their PEF using a mini-Wright peak flow meter. Patients were excluded from the study if they had any other coexisting respiratory condition (including cystic fibrosis and bronchiectasis), any coexisting cardiac disease, or any other serious systemic illness. Patients were also excluded if they had suffered from an upper or lower respiratory tract infection within the previous 14 days, which was likely to affect their baseline lung function and symptom score. Those who were seasonally allergic and had a high probability of suffering an exacerbation of their asthma during the study were also excluded.

\section{STUDY DESIGN}

This was a double blind crossover study to compare the effects of fluticasone and beclomethasone on adrenocortical activity of asthmatic children, using inhaled corticosteroids at high doses $\left(>400 \mu \mathrm{g} / \mathrm{m}^{2} / \mathrm{d}\right)$. Patients entered a run in period of two weeks during which time they continued to take their normal inhaled corticosteroid (beclomethasone or budesonide) through conventional devices. At the end of the run in period the patients were randomised to receive either an equal dose of beclomethasone or an equipotent (half the dose) of fluticasone given through a metered dose inhaler and a Volumatic spacer device twice daily.
The first study treatment was taken for six weeks and replaced the patient's usual inhaled steroid treatment. All other asthma treatment was maintained at constant dose except for $\beta_{2}$ agonist treatment, which was taken as required for symptom relief. After the first six weeks the patients received the alternative treatment for a further six weeks. There was no washout period between the study periods.

\section{ASSESSMENTS}

Patients measured their PEF three times, twice daily, throughout the study using the miniWright peak flow meter, and recorded their best scores on a diary card. In addition they recorded the severity of their day and night asthma symptoms. Symptoms during the day (cough, wheeziness, and activity problems) and night (cough) were rated using a four point scale. Patients also recorded their use of the study medication and of the rescue medication (salbutamol or terbutaline).

Patients attended the clinic on five occasions: at the start and the end of the run in period, at the end of each of the two study medication periods, and two weeks afterwards at the end of the follow up period. At each clinic visit, triplicate spirometry measurements (PK Morgan spirometer) were performed and the best values for PEF forced vital capacity (FVC ), and forced expiratory volume in one second $\left(\mathrm{FEV}_{1}\right)$ were recorded after correction for body temperature and water saturation (BTPS).

A full physical examination was performed at each study visit and where infection was suspected, a throat swab was taken for Candida albicans. Any untoward clinical events experienced by the patients between the clinic visits were recorded, irrespective of their cause in relation to the study drugs. Any patient withdrawals from the study were investigated at a clinic visit or a contact by telephone or letter, and all reasons for withdrawal were recorded.

Adrenocortical activity was assessed by measuring the 24 hour urinary cortisol metabolites excretion at the end of the run in period (baseline) and the end of each of the two six week study periods.

URINE SAMPLES ANALYSIS

Urine collections were performed in the 48 hour period before the clinic visits and this was usually arranged to coincide with a weekend. At the previous visit patients were given urine collecting containers and clear oral and written instructions on how to make the collection. Urine samples were frozen until analysed in batches of five to ten. Urine samples were assessed for the excretion of (a) the total cortisol metabolites, (b) cortisol, (c) androgen, and (d) creatinine. 'Total cortisol metabolites' was the sum of the following: tetrahydrocortisone, tetrahydrocortisol, allo-tetrahydrocortisol ( $5 \alpha$ THF), $\alpha$ cortolone, $\alpha$ cortol, $\beta$ cortol, and $\beta$ cortolone. 'Cortisol metabolites' was the sum of the excreted tetrahydrocortisol and $5 \alpha$-THF divided by the patient's body surface in $\mathrm{m}^{2}$. 
'Androgen' was the sum of androsterone and aetiocholanolone excretion rates. Creatinine was measured in order to correct for any intrasubject urine collection inconsistencies.

Urinary steroids were determined by quantitative gas-liquid chromatography (GLC) as described previously. ${ }^{21}$ The Jaffe reaction was used for the assessment of the urinary creatinine. ${ }^{22}$

\section{STATISTICAL ANALYSIS}

All statistical tests were two sided and the conventional 5\% level of statistical significance was used for all treatment comparisons. Each of total cortisol, cortisol, and androgen were analysed with and without correction for creatinine, where this was applicable. Correction for creatinine was performed by multiplying the total cortisol/cortisol/androgen excretion rates for a specific visit by the average creatinine excretion rate over clinic visits 2,3 , and 4 and dividing by the creatinine excretion rate at that visit. Comparison of the metabolites between the two subgroups (beclomethasonebudesonide) at baseline was performed with the unpaired $t$ test. Correlations between inhaled steroid dosage and cortisol metabolites at baseline were sought by linear regression. A test for different treatment carryover effects was done by examining the sequence effect at the $10 \%$ level of significance. Analysis of variance (ANOVA) was used for the comparisons of log cortisol metabolites between the two study medications. Estimates and corresponding $95 \%$ confidence intervals for the ratio of treatment population means were calculated. The cortisol metabolites at baseline and at the end of each study period were also compared within subgroups $A$ and $B$ by using ANOVA.

For the statistical analysis of diary card data, the first two weeks of each period were used as a washout, and so only data from weeks three to six and weeks nine to 12 respectively were included in the formal statistical analysis. Mean morning and evening PEF, clinic visit PEF, FVC, and $\mathrm{FEV}_{1}$ were each compared between treatments using a crossover model, adjusting for treatment sequence, patient, and treatment period. Cough, wheeze, and activity scores were each summarised as percentages of symptom-free (score 0) days and as median symptom scores. Medians and percentages for a patient were calculated, frequency distributions for each treatment were determined, and differences between treatments were compared using the crossover analogue of the Wilcoxon rank-sum test. ${ }^{23}$ Hodges-Lehmann estimates and corresponding $95 \%$ confidence intervals for the difference between treatment population medians were calculated. Use of $\beta_{2}$ agonist rescue medication was summarised and analysed in the same way as the diary card symptom scores.

\section{Results}

Seventeen patients received fluticasone first and crossed over to beclomethasone (fluticasone/ beclomethasone) and 17 received the treat-
Table 1 Comparison of urinary cortisol metabolite values in all the children at the two treatment periods

\begin{tabular}{llll}
\hline & FP & BDP & $p$ Value \\
\hline $\begin{array}{l}\text { Total cortisol metabolites } \\
(\mu \mathrm{g} / \mathrm{d})\end{array}$ & 1315 & 1245 & 0.55 \\
Cortisol metabolites $\left(\mu \mathrm{g} / \mathrm{m}^{2} / \mathrm{d}\right)$ & 399 & 352 & 0.24 \\
\hline
\end{tabular}

* Adjusted geometric mean values.

$\mathrm{FP}=$ fluticasone BDP = beclomethasone .

Table 2 Comparison of urinary cortisol metabolites in all the children at the two treatment periods after correction for creatinine

\begin{tabular}{llll}
\hline & $F P^{\star}$ & $B D P^{\star}$ & $p$ Value \\
\hline $\begin{array}{l}\text { Total cortisol metabolites } \\
(\mu \mathrm{g} / \mathrm{d})\end{array}$ & 1400 & 1208 & 0.14 \\
Cortisol metabolites $\left(\mu \mathrm{g} / \mathrm{m}^{2} / \mathrm{d}\right)$ & 424 & 341 & 0.04 \\
\hline
\end{tabular}

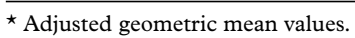

$\mathrm{FP}=$ fluticasone; BDP = beclomethasone.

ments in the reverse order (beclomethasone/ fluticasone). Eight patients were withdrawn from the study after randomisation, five of whom received the beclomethasone/fluticasone sequence and three of whom received the fluticasone/beclomethasone sequence. Four were withdrawn because of protocol violations and four because of adverse events. One patient withdrew because of an adverse event which occurred during treatment with fluticasone and three patients during treatment with beclomethasone. Adverse events included asthma exacerbation (three patients) and coughing and headache after taking beclomethasone (one patient).

The two baseline treatment subgroups, $\mathrm{A}$ and $\mathrm{B}$, and the two study medication sequence groups, fluticasone/beclomethasone and beclomethasone/fluticasone, were well matched for male to female ratio, age, height, weight, duration of asthma, and history of atopy.

\section{CORTISOL METABOLITES}

There were no statistically significant differences in total cortisol and cortisol metabolites between the two study medications (table 1). No statistically significant carryover effects for total cortisol and cortisol metabolites were detected ( $p=0.204$ and 0.263 respectively). However, patients taking fluticasone had higher cortisol metabolite levels after correction for creatinine excretion than those taking beclomethasone during the study periods $(\mathrm{p}=$ 0.04) (table 2). Total cortisol metabolites corrected for creatinine excretion after treatment with fluticasone were higher than the values obtained after treatment with beclomethasone, although the difference did not reach statistical significance (table 2). Again no statistically significant carryover effects for creatinine corrected total cortisol and cortisol metabolites were detected $(\mathrm{p}=0.354$ and 0.445).

Some of patients had androgen metabolites below detection level and it was judged that a formal statistical analysis would not be informative. However, those patients with detect- 
Table 3 Androgen metabolites following treatment with fluticasone (FP) and beclomethasone (BDP)

\begin{tabular}{lll}
\hline & $F P(\mu g / d)$ & $B D P(\mu g / d)$ \\
\hline $\begin{array}{l}\text { Number } \\
\text { Mean }\end{array}$ & 14 & 17 \\
(SD) & $(275)$ & 276 \\
\hline
\end{tabular}

able androgen metabolites had similar values following treatment with either fluticasone or beclomethasone (table 3).

DIARY CARD PEF AND SYMPTOM SCORES

The mean values for morning PEF for the last four weeks of each treatment period were identical (fluticasone $=268 \mathrm{l} / \mathrm{min}$, beclomethasone $=268 \mathrm{l} / \mathrm{min}$ ) and no significant carryover effect was detected $(\mathrm{p}=0.144)$. There were similar results for the mean evening PEF values except that there was a trend towards a carryover effect $(p=0.096)$.

There was no significant difference between the two study drugs in the medians for coughfree days for each week of the treatment period $(\mathrm{p}=0.368$; fluticasone $=73 \%$, beclomethasone $=85 \%$ ) with confidence limits for the fluticasone-beclomethasone treatment difference of $-16 \%$ to $6 \%$.

Results were similar for percentage of wheeze-free days, symptom-free activity days, and cough-free nights. No significant differences were seen between study treatments with regard to additional usage of salbutamol during the day or overnight.

There were no significant differences in clinic visit lung function variables between study drugs and no significant carryover effect was detected.

SAFETY RESULTS

Overall, fluticasone was as safe and as well tolerated as beclomethasone. The incidence of individual drug related adverse events was similar in the two treatment groups. There were no serious adverse events reported at any time during the study.

ANALYSIS OF BASELINE DATA

The total cortisol and cortisol metabolites at baseline were significantly higher in the children who were taking budesonide for at least three months (subgroup A) than in the children who had been taking beclomethasone (subgroup B) (table 4). There was a significant correlation $(\mathrm{p}=0.01)$ between the dose of budesonide per $\mathrm{m}^{2}$ and total cortisol metabolites in subgroup A, suggesting a dose related suppression of adrenal function with increasing dose of inhaled budesonide (fig 1). No significant relation was found between the dose of beclomethasone per $\mathrm{m}^{2}$ and cortisol metabolites in subgroup B (fig 2). There were no significant differences in the excretion rates of urinary cortisol metabolites between the baseline values and those obtained after the two treatment periods for the patients in group A, neither did any significant differences emerge
Table 4 Baseline urinary cortisol metabolite values in the children of subgroups $A$ (budesonide) and $B$

(beclomethasone)

\begin{tabular}{llll}
\hline & $\begin{array}{l}\text { Subgroup } A^{*} \\
(n=19)\end{array}$ & $\begin{array}{l}\text { Subgroup } B^{*} \\
(n=15)\end{array}$ & $p$ Value \\
\hline $\begin{array}{c}\text { Total cortisol } \\
\text { metabolites }(\mu \mathrm{g} / \mathrm{d})\end{array}$ & 1542 & 975 & 0.01 \\
$\begin{array}{c}\text { Cortisol metabolites } \\
\left(\mu \mathrm{g} / \mathrm{m}^{2} / \mathrm{d}\right)\end{array}$ & 420 & 314 & 0.04 \\
\hline
\end{tabular}

^ Geometric mean values.

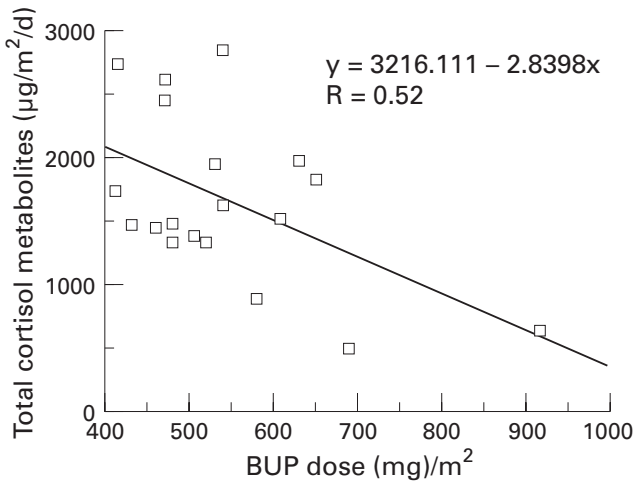

Figure 1 Dose related suppression of adrenal function at baseline in children taking budesonide $(p<0.01)$.

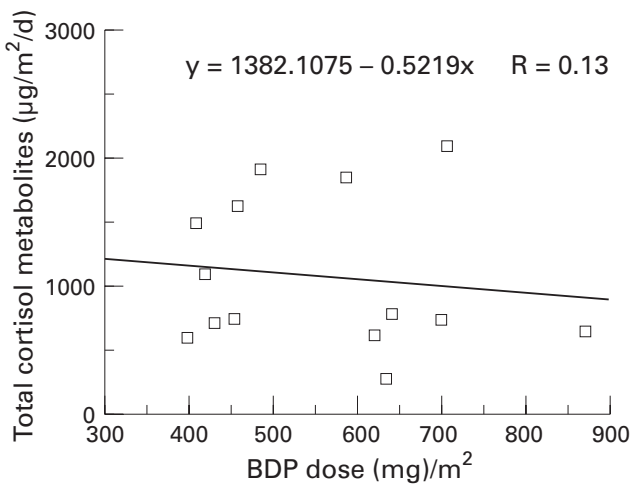

Figure 2 No relation between the dose of beclomethasone at baseline and cortisol metabolites.

after the results had been corrected for creatinine excretion (tables 5 and 6). However, in the patients of subgroup B, the baseline values of the cortisol and the total cortisol metabolites were significantly reduced when compared with the metabolites obtained at the end of each of the study medication periods, after correction for creatinine excretion rates (tables 5 and 6).

\section{Discussion}

The comparison of steroid excretion rates between the two treatment periods (fluticasone and beclomethasone) in all children, although favouring fluticasone in all measured indices, reached statistical significance in cortisol metabolites (tetrahydrocortisol and $5 \alpha$-THF) only after correction for urinary creatinine excretion. This correction had been carried out to reduce error from any inconsistencies of intrasubject urine collection. 
Table 5 Analysis of variance of urinary cortisol metabolite values in the children of subgroups $A$ (budesonide) and B (beclomethasone) at the three test occasions

\begin{tabular}{lllll}
\hline & Baseline* & $F P^{*}$ & BDP* & $p$ Value \\
\hline Group A $(\mathrm{n}=16)$ & 1457 & 1296 & 1205 & 0.5 \\
$\quad$ Total cortisol $(\mu \mathrm{g} / \mathrm{d})$ & 425 & 391 & 318 & 0.2 \\
$\quad$ Cortisol $\left(\mu \mathrm{g} / \mathrm{m}^{2} / \mathrm{d}\right)$ & & & & \\
Group B $(\mathrm{n}=10)$ & 812 & 1348 & 1248 & 0.06 \\
$\quad$ Total cortisol $(\mu \mathrm{g} / \mathrm{d})$ & 255 & 397 & 409 & 0.04 \\
Cortisol $\left(\mu \mathrm{g} / \mathrm{m}^{2} / \mathrm{d}\right)$ & & &
\end{tabular}

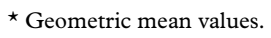

$\mathrm{FP}=$ fluticasone.

Table 6 Analysis of variance of urinary cortisol metabolite values corrected for creatinine excretion rates in the children of subgroups $A$ (budesonide) and $B$ (beclomethasone) at the three test occasions

\begin{tabular}{lllll}
\hline & Baseline & $F P^{\star}$ & BDP* & $p$ Value \\
\hline Group A $(\mathrm{n}=16)$ & 1626 & 1425 & 1139 & 0.18 \\
$\quad$ Total cortisol metabolites $(\mu \mathrm{g} / \mathrm{d})$ & 468 & 412 & 305 & 0.08 \\
$\quad$ Cortisol metabolites $\left(\mu \mathrm{g} / \mathrm{m}^{2} / \mathrm{d}\right)$ & & & & \\
Group B $(\mathrm{n}=10)$ & 789 & 1437 & 1269 & 0.04 \\
$\quad$ Total cortisol metabolites $(\mu \mathrm{g} / \mathrm{d})$ & 248 & 423 & 415 & 0.02 \\
$\quad$ Cortisol metabolites $\left(\mu \mathrm{g} / \mathrm{m}^{2} / \mathrm{d}\right)$ & &
\end{tabular}

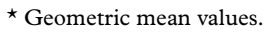

$\mathrm{FP}=$ fluticasone. tent dose of fluticasone was given through a spacer. This supports previous claims that the use of a cheap device such as a Volumatic is sufficient to relieve most of any impairment in the diurnal steroid production induced by high doses of beclomethasone. Similar findings have already been shown by others in adults. ${ }^{16}{ }^{24}$ No significant change was seen in steroid excretion in the children of subgroup A (budesonide) with the usage of a spacer and fluticasone, probably because the majority of the baseline values were already well within the normal range.

There remains considerable doubt about whether the reduced steroid excretion rates in some asthmatic children taking high doses of inhaled corticosteroids are of any clinical significance since, with the exception of very rare children who appear to have an idiosyncratic response, ${ }^{25}$ no study so far has shown an impaired adrenal response to adrenocorticotropic hormone stimulation in these patients. It would seem more reasonable to assume that the reduced steroid excretion rates in some patients are physiological adjustments of the unstimulated diurnal production of glucocorticosteroids to small amounts of circulating external steroids, and the long term significance of this remains to be elucidated in the future.

At results between the two treatment peric Although this study is too small to exclude a type 2 error, our results suggest that fluticasone is equipotent to twice the dose of beclomethasone over this range of doses with regard to the control of asthma in children. Lung function indices were better during the two treatment periods compared with the baseline values but these data are not comparable since it is well known that the use of a spacer device leads to a better deposition of inhaled medications in the lungs. ${ }^{15}$ Also, lung function often improves even in placebo treatment groups in patients taking part in a clinical trial.

The baseline findings of this study suggest that adrenal function was better in children taking budesonide through conventional devices than in children taking similar doses of beclomethasone. Similar findings have already been reported in three other studies. ${ }^{91013}$ There was a dose related suppression of adrenal function with increasing dose of budesonide which appeared to be significant at doses exceeding $600 \mu \mathrm{g} / \mathrm{m}^{2} / \mathrm{d}$. No dose related suppression was found in the children who were taking beclomethasone. In a previous study where a dose related suppression of adrenal function was reported in children taking beclomethasone, the children were on a wider range of doses $\left(200-900 \mu \mathrm{g} / \mathrm{m}^{2} / \mathrm{d}\right){ }^{11}$ However, that study was not designed to examine the comparative effects on adrenal function of inhaled beclomethasone and budesonide, particularly as the children were not randomised to their baseline treatment.

The comparison of the baseline results and those obtained subsequently produced some interesting associations. In the subgroup B children, the usage of a spacer device to give the same dose of beclomethasone caused a significant improvement in steroid excretion rates, which improved further when an equipo-

\section{CONCLUSION}

In conclusion, fluticasone is a new inhaled corticosteroid which it is less likely to suppress spontaneous diurnal steroid excretion when given at therapeutically equivalent doses to asthmatic children receiving beclomethasone at doses of between 400 and $900 \mu \mathrm{g} / \mathrm{m}^{2} / \mathrm{d}$. In addition, the baseline data support the recommendation that spacer devices should be used for the administration of doses of inhaled beclomethasone in excess of $400 \mu \mathrm{g} / \mathrm{m}^{2} / \mathrm{d}$.

We are very grateful to Glaxo Group Research who funded PKY's salary, provided the treatment aerosols, and helped with the statistical analyses.

1 International Paediatric Asthma Consensus Group. Asthma a follow-up statement. Arch Dis Child 1992;67:240-8.

2 Geddes DM. Inhaled corticosteroids: benefits and risks. Thorax 1992;47:404-7.

3 Klein R, Waldman D, Kershnar H, et al. Treatment of chronic childhood asthma with beclomethasone dipropionate aerosol: a double-blind crossover trial in nonsteroiddependent patients. Pediatrics 1977;60:7-13.

4 Golstein DE, Konig P. Effect of inhaled beclomethasone dipropionate on hypothalamic-pituitary-adrenal axis funcdipropionate on hypothalamic-pituitary-adrenal axis
tion in children with asthma. Pediatrics 1983;72:60-4.

5 Gustafson P, Tsanakas J, Gold M, Primhak R, Radford M, Gillies E. Comparison of the efficacy and safety of inhaled fluticasone propionate $200 \mu \mathrm{g} /$ day with inhaled beclomethasone dipropionate $400 \mu \mathrm{g} /$ day in mild and moderate asthma. Arch Dis Child 1993;69:206-11.

6 Tabachnik E, Zadik Z. Diurnal cortisol secretion during therapy with inhaled beclomethasone dipropionate in children with asthma. F Pediatr 1991;118:294-7.

7 Law CM, Marchant JL, Honour JW, Preece MA, Warner JO. Nocturnal adrenal suppression in asthmatic children taking inhaled beclomethasone dipropionate. Lancet 1986: ii: $942-4$.

8 Nicolazik WH, Marchant JL, Preece MA, Warner JO. Endocrine and lung function in asthmatic children on inhaled corticosteroids. Am f Resp Crit Care Med 1994;150;624-8.

9 Springer C, Avital A, Maayan CH, Rosler A, Godfrey S. Comparison of budesonide and beclomethasone dipropiComparison of budesonide and beclomethasone dipropi9 .

10 Pedersen S, Fuglsang G. Urine cortisol excretion in children treated with high doses of inhaled corticosteroids: a comparison of budesonide and beclomethasone. Eur Respir f 1988;1:433-5. 
11 Bisgaard $\mathrm{H}$, Pedersen S, Nielsen MD, Osterballe O. Adrenal function in asthmatic children treated with inhaled function in asthmatic children treated with

12 Honour JW. The adrenal cortex. In: Brook CGD, ed. Clinical paediatric endocrinology. Oxford: Blackwell, 1989:35767.

13 Bisgaard H, Nielsen MD, Andersen B, et al. Adrenal function in children with bronchial asthma treated with beclomethasone dipropionate or budesonide. $\mathcal{F}$ Allergy Clin Immunol 1988;81:1088-95.

14 Priftis K, Milner AD, Conway E, Honour JW. Adrenal function in asthma. Arch Dis Child 1990;65:838-40.

15 Newman SP, Pavia D, Moren F. Deposition of pressurised aerosols in the human respiratory tract. Thorax 1981;36: $52-5$.

16 Newman SP, Millar AB, Lennard-Jones TR. Improvement of pressurised aerosol deposition with nebuhaler spacer device. Thorax 1984;39:935-41.

17 Brown PH, Blundell G, Greening AP, Crompton GK. Do large volume spacer devices reduce the systemic effects of high dose inhaled corticosteroids? Thorax 1990;45:736-9.

18 Barnes NC, Marone G, Di Maria GU, Visser S, Utama I, Payne S. A comparison of fluticasone propionate $1 \mathrm{mg}$ daily with beclomethasone dipropionate $2 \mathrm{mg}$ daily in the treatment of severe asthma. Eur Respir f 1993;6:877-84.

19 Harding SM. The human pharmacology of fluticasone propionate [abstr]. Allergologie 1989;12:77.

20 Harding SM. The human pharmacology of fluticasone propionate. Respir Med 1990;84(suppl A):25-9.

21 Honour JW, Kelnar CJH, Brook CGD. Urine steroid excretion rates in childhood reflect growth and activity of the adrenal cortex. Acta Endocrinol (Copenh) 1990;124:21924.

22 Henry RJ. Clinical chemistry-principles and techniques. 2nd Ed. New York: Harper, 1974:543.

23 Koch GG. The use of non-parametric methods in the statistical analysis of the two-period change-over design. Biometrics 1972;28:577-84.

24 Farrer M, Francis AJ, Pearce SJ. Morning cortisol concentrations after $2 \mathrm{mg}$ inhaled beclomethasone dipropionate in normal subjects: effect of a $750 \mathrm{ml}$ spacing device. Thorax 1990;45:740-2.

25 Priftis K, Everard ML, Milner AD. Unexpected side effects of inhaled steroids: a case report. Eur f Pediatr 1991;150: of inhaled $448-9$. 